\title{
Carotid Intima-media Thickness in the Spanish Population: Reference Ranges and Association With Cardiovascular Risk Factors
}

\author{
Maria Grau, ${ }^{\text {a,* }}$ Isaac Subirana, ${ }^{\text {a,b }}$ David Agis, ${ }^{\text {b,c }}$ Rafel Ramos, ${ }^{\text {d }}$ Xavier Basagaña, ${ }^{\text {b,c }}$ Ruth Martí, ${ }^{\text {d }}$ \\ Eric de Groot, ${ }^{\mathrm{e}}$ Roman J. Arnold, ${ }^{\mathrm{f}}$ Jaume Marrugat, ${ }^{\mathrm{a}}$ Nino Künzli,, ${ }^{\mathrm{g}, \mathrm{h}}$ and Roberto Elosua ${ }^{\mathrm{a}, \mathrm{b}}$
}

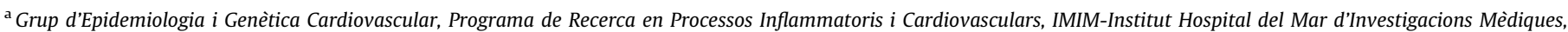
Barcelona, Spain

${ }^{\mathrm{b}}$ CIBER Epidemiología y Salud Pública (CIBERESP), Spain

${ }^{\mathrm{C}}$ Centre de Recerca en Epidemiologia Ambiental (CREAL), Barcelona, Spain

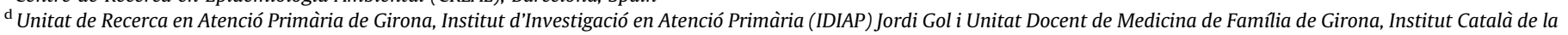
Salut (ICS), Girona, Spain

${ }^{\mathrm{e}}$ Academic Medical Centre, University of Amsterdam, Amsterdam, The Netherlands

${ }^{\mathrm{f}}$ ICICORELAB, Hospital Clínico Universitario, Valladolid, Spain

${ }^{g}$ Swiss Tropical and Public Health Institute (SwissTPH), Basel, Switzerland

${ }^{\mathrm{h}}$ University of Basel, Basel, Switzerland

Article history:

Received 21 February 2012

Accepted 18 April 2012

Available online 28 September 2012

\section{Keywords:}

Carotid intima-media thickness

Carotid ultrasonography

Cardiovascular risk factors

Preclinical atherosclerosis

Cardiovascular risk

\begin{abstract}
A B S T R A C T
Introduction and objectives: Carotid intima-media thickness as measured with ultrasonography is an inexpensive and noninvasive predictor of cardiovascular events. The objectives of this study were to determine the population reference ranges of carotid intima-media thickness for individuals aged 35-84 years in Spain and to analyze the association of carotid intima-media thickness with cardiovascular risk factors (age, smoking, diabetes, pulse pressure, lipid profile, and body mass index).

Methods: Population-based cross-sectional study conducted in Gerona (Spain). We described the mean and maximal values of carotid intima-media thickness of the carotid artery and of its 3 segments (common carotid, carotid bulb and internal carotid). We assessed cardiovascular risk factors and analyzed their association with carotid intima-media thickness using adjusted linear regression models. Results: A total of 3161 individuals (54\% women) were included, with mean age 58 years. Men showed significantly higher mean common carotid intima-media thickness than did women $(0.71 \mathrm{vs} 0.67 \mathrm{~mm})$. The strongest predictors of this measure were age (coefficients for 10-year increase: 0.65 and 0.58 for women and men, respectively), smoking in men (coefficient: 0.26), high-density lipoprotein cholesterol in women (coefficient for $10 \mathrm{mg} / \mathrm{dL}$, increase: -0.08) and pulse pressure in both sexes (coefficients for $10 \mathrm{mmHg}$ increase: 0.08 and 0.23 for women and men, respectively). The results were similar for the mean carotid intima-media thickness of all the segments.

Conclusions: This population-based study presents the reference ranges for carotid intima-media thickness in the Spanish population. The main determinants of carotid intima-media thickness were age and pulse pressure in both sexes.
\end{abstract}

(C) 2012 Sociedad Española de Cardiología. Published by Elsevier España, S.L. All rights reserved.

\section{Grosor íntima-media carotídeo en población española: valores de referencia y asociación con los factores de riesgo cardiovascular}

\section{RES U M E N}

Introducción y objetivos: El grosor íntima-media carotídeo medido por ultrasonografía es un predictor de acontecimientos cardiovasculares barato y no invasivo. Se analizaron los valores de referencia del grosor íntima-media carotídeo en población española de 35-84 años y su asociación con los factores de riesgo cardiovascular (edad, tabaquismo, diabetes mellitus, presión de pulso, perfil lipídico e índice de masa corporal).

Métodos: Estudio transversal de base poblacional llevado a cabo en Girona (España). Se describieron los grosores íntima-media medio y máximo de la arteria carótida y sus tres segmentos (carótida común, interna y bulbo carotídeo). Se recogió información sobre factores de riesgo cardiovascular y se analizó su asociación con el grosor íntima-media carotídeo mediante modelos de regresión lineal.

Resultados: Se incluyó a 3.161 sujetos (el 54\% mujeres), con una media de edad de 58 años. La media del grosor íntima-media carotídeo común fue mayor en los varones que en las mujeres $(0,71$ frente a $0,67 \mathrm{~mm}$ ). Los principales predictores de esta medida fueron la edad (coeficiente para incremento de 10 años, 0,65 y 0,58 en varones y mujeres respectivamente), el tabaquismo en los varones (coeficiente, 0,26), el colesterol unido a lipoproteínas de alta densidad en las mujeres (coeficiente para incremento de

\footnotetext{
* Corresponding author: Grup d'Epidemiologia i Genètica Cardiovascular, IMIM, Dr. Aiguader 88, 08003 Barcelona, Spain.

E-mail address: mgrau@imim.es (M. Grau).
} 
$10 \mathrm{mg} / \mathrm{dl}$, incremento de -0,08) y la presión de pulso en ambos sexos (coeficientes para incremento de $10 \mathrm{mmHg}, 0,23$ los varones y 0,08 las mujeres). Los resultados fueron similares en las medias de grosor íntima-media carotídeo de los tres segmentos.

Conclusiones: Este estudio de base poblacional muestra la amplitud de valores de referencia para el grosor íntima-media carotídeo en población española. Sus principales determinantes son la edad y la presión de pulso en ambos sexos.

๔ 2012 Sociedad Española de Cardiología. Publicado por Elsevier España, S.L. Todos los derechos reservados.

\section{Abbreviations}

ACA: all carotid artery

CB: carotid bulb

CCA: common carotid artery

HDL-C: high-density lipoprotein cholesterol

ICA: internal carotid artery

IMT: intima-media thickness

\section{INTRODUCTION}

Cardiovascular diseases are the main cause of death in western countries. ${ }^{1}$ The common basis of this group of diseases is atherosclerosis, a chronic and degenerative process that mainly occurs in large and medium-sized arteries morphologically characterized by asymmetric focal thickenings of the innermost layer of the artery, the intima. ${ }^{2}$

The long induction period of atherosclerosis makes it suitable for the study of subclinical disease for preventive purposes. For instance, carotid ultrasound can be used to detect subclinical disease because it provides measures of intima-media thickness (IMT) and the presence of atherosclerotic plaques. The advantages of carotid ultrasonography are that it is noninvasive, relatively inexpensive, and does not irradiate; hence this measure can be repeatedly performed with no adverse effects on the participant. ${ }^{3,4}$ Previous studies have shown the association of carotid IMT with cardiovascular risk factors and with the incidence of cardiovascular events. ${ }^{5-7}$ Particularly, the results of a meta-analysis have shown that for an absolute carotid IMT difference of $0.1 \mathrm{~mm}$, the risk of future myocardial infarction increased by $10 \%$ to $15 \%$, and the stroke risk increased by $13 \%$ to $18 \%{ }^{8}$

In Spain, carotid IMT values have been previously described in nonrepresentative samples of modest size. ${ }^{9-11}$ We undertook the study of the reference ranges of carotid IMT values and their association with cardiovascular risk factors in a Spanish population sample with a wide age range and guaranteed population representativeness.

The objectives of this study were: $a$ ) to describe the population reference ranges of mean and maximal IMT values of the common carotid artery (CCA) and of all carotid artery (ACA) segments including the CCA, carotid bulb (CB) and internal carotid artery (ICA), by age and sex in individuals aged 35-84 years in Spain, and 2) to analyze the association of CCA and ACA IMT with cardiovascular risk factors in a population-based sample.

\section{METHODS}

\section{Study Design and Population}

The Gerona Heart Registry (Registre Gironi del Cor [REGICOR]) project includes a series of population-based cohorts randomly recruited from the most recent census to participate in 3 crosssectional studies, in 1995, 2000 and $2005 .{ }^{12}$ Our analyses are based on the cross-sectional data of carotid IMT collected for the first time at the follow-up assessments of these cohorts, conducted between 2007 and 2010. This follow-up involved participants from all 6 counties of Gerona province (Spain), representing a population of approximately 600000 inhabitants. Participants included between 2007 and 2010 were aged 35-84 years, lived in the referral area for at least 6 months, were free of terminal disease, and were not institutionalized. We excluded participants with previous a history of cardiovascular disease for the purpose of the present analysis.

Participants were contacted by a letter informing them of the aims of the study and the tests to be performed. They were asked to fast for at least $10 \mathrm{~h}$ before their appointment at the health examination site; a telephone number for inquiries was supplied. Participants were also contacted 1 week before the examination to confirm attendance. All participants were duly informed and provided their written consent to participate in the study and the results of the examination were sent to each of them. The study was approved by the local ethics committee.

\section{Carotid Ultrasound}

Two trained sonographers performed the carotid ultrasound examinations with an Acuson XP128 ultrasound machine equipped with an $\mathrm{L} 75-10 \mathrm{MHz}$ transducer and extended frequency software (Acuson-Siemens, Mountainview, California, United States). B-mode ultrasound images of the CCA, CB and ICA segments were obtained (Fig. 1, supplementary material). Image files were recorded and sent to the Academic Vascular Image Centre in Amsterdam for analysis. Measurements were made in a $1-\mathrm{cm}$ segment in the distal CCA $(1 \mathrm{~cm}$ proximal to dilation of the $\mathrm{CB}), 1 \mathrm{~cm}$ in the $\mathrm{CB}(1 \mathrm{~cm}$ proximal to the flow divider) and $1 \mathrm{~cm}$ in the proximal ICA (immediately distal to the flow divider) of both right and left arteries. Measurements were made every $1 \mathrm{~mm}$ in each $1 \mathrm{~cm}$ segment, from which the mean and the maximum values were calculated. The image analyses were performed by expert trained readers with validated software (eTRACK) used in previous studies. ${ }^{13}$

The measures considered in these analyses were the mean and maximal IMT of the CCA and of ACA segments (CCA, CB and ICA) assessed in the left and right carotid arteries. Mean carotid IMT was defined as the average of right and left IMT measures and maximal IMT as the average of the maximum value observed in the right and left CCA segments. Similarly, mean ACA IMT was defined as the average of all measures of IMT in the 3 right and left segments of the carotid artery (CCA, CB, and ICA), and the maximal ACA IMT was computed as the average of the maximum values observed in these 6 segments.

The mean and maximal carotid IMT for at least 1 of all 6 carotid sites was missing in $22.8 \%$ of participants. The values at the missing sites were imputed from multivariate linear models of mean and maximal carotid IMT as a function of sex, age, and body mass index (BMI) fit by the multiple imputation method. ${ }^{14} \mathrm{~A}$ total of 983 (5.2\%) carotid IMT measures were imputed. The means 
at the 6 sites were combined in an unweighted average to estimate the ACA IMT.

We performed a repeatability analysis in 42 subjects that were examined by 3 sonographers in 2 different visits. Due to missing data, in the final dataset subjects had an average of 4.3 measures (ranging from 2-6). The intraclass correlation coefficients between sonographers and within each sonographer's results for the mean CCA were 0.83 and 0.85 , respectively. The coefficient of variation was $7.3 \%$ and the maximum within-subject (absolute) difference had an average of $0.098 \mathrm{~mm}$.

\section{Measurements}

Examinations were performed by a team of trained nurses and interviewers. A precision scale of easy calibration was used for weight and height measurement with participants in underwear and barefoot. BMI was determined as weight divided by squared height $\left(\mathrm{kg} / \mathrm{m}^{2}\right)$. Blood pressure was measured with a periodically calibrated sphygmomanometer (OMRON 711). A cuff adapted to the upper arm perimeter (young, adult, obese) was selected for each participant. Measurements were performed in a seated position after a 5-min rest. Two measurements were taken and the lower value was recorded for the study. Pulse pressure was calculated as the difference between systolic and diastolic blood pressure (mmHg).

Standardized questionnaires were used to collect sociodemographic and lifestyle variables, and the previous history and treatments for diabetes, hypertension and hypercholesterolemia. Current smoking was defined as actively smoking within the preceding year.

Blood was withdrawn after 10-14 h of fasting. Total cholesterol and high-density lipoprotein cholesterol (HDL-C) concentrations were determined by direct methodology (Roche Diagnostics, Basel, Switzerland).
Coronary risk in participants aged $35-74$ years was calculated by the REGICOR function adapted from the original Framingham function and validated for the Spanish population. ${ }^{15}$

\section{Statistical Analysis}

Continuous variables were summarized as mean (standard deviation) or median [interquartile range] when their distribution departed from normal, and categorical variables as proportions. The 5th, 10th, 25th, 50th, 75th, 90th, and 95th percentiles of the mean and maximal carotid IMT measures were estimated and stratified by 10-year age groups and sex, as in previous studies. ${ }^{5,16-18}$ Percentiles were also estimated for the subset of individuals who did not smoke, had optimal levels of cardiovascular risk factors (ie, $\mathrm{HDL}-\mathrm{C}>40 \mathrm{mg} / \mathrm{dL}, \mathrm{BMI}<30 \mathrm{~kg} / \mathrm{m}^{2}$ ) and did not have hypertension, diabetes or hypercholesterolemia. We also computed the correlation index between the carotid IMT measures and the 10-year coronary risk in the subset of individuals aged $35-74$ years.

To estimate the association between the different measures of carotid IMT and the prevalence of cardiovascular risk factors, we fitted 2 linear regression models for each carotid IMT measurement and sex. The first was only adjusted for age and the second was further adjusted for pulse pressure, diabetes, smoking, total and HDL-C and BMI.

Statistical analysis was done with the $\mathrm{R}$ Statistical Package ( $R$ Foundation for Statistical Computing, Vienna, Austria; Version 2.13.0).

\section{RESULTS}

A total of 3161 individuals were included (54\% women) with a mean age 58 years. The IMT of the 3 segments of the carotid artery

Table 1

Comparison of Participant Characteristics by Sex and the Presence of Cardiovascular Risk Factors

\begin{tabular}{|c|c|c|c|}
\hline & $\begin{array}{l}\text { Women } \\
n=1708\end{array}$ & $\begin{array}{l}\text { Men } \\
n=1453\end{array}$ & $P$ \\
\hline Age, years & $59(12)$ & $58(12)$ & .089 \\
\hline Smoker & $13.8 \%$ & $24.2 \%$ & $<.001$ \\
\hline Diabetes & $7.0 \%$ & $11.0 \%$ & $<.001$ \\
\hline Hypertension & $40.8 \%$ & $48.4 \%$ & $<.001$ \\
\hline Systolic blood pressure, $\mathrm{mmHg}$ & $124(20)$ & $131(18)$ & $<.001$ \\
\hline Diastolic blood pressure, $\mathrm{mmHg}$ & $76(10)$ & $80(10)$ & $<.001$ \\
\hline Pulse pressure, $\mathrm{mmHg}$ & $48(16)$ & $51(15)$ & $<.001$ \\
\hline Total cholesterol, mg/dL & $216(37)$ & $208(36)$ & $<.001$ \\
\hline HDL-C, mg/dL & $58(12)$ & $49(9)$ & $<.001$ \\
\hline BMI, $\mathrm{kg} / \mathrm{m}^{2}$ & $26.8(4.8)$ & $27.4(3.8)$ & $<.001$ \\
\hline REGICOR coronary risk & $2.17[1.24-3.52]$ & $3.91[2.26-6.24]$ & $<.001$ \\
\hline Mean ACA IMT, mm & $0.67[0.59-0.76]$ & $0.72[0.63-0.81]$ & $<.001$ \\
\hline Maximal ACA IMT, mm & $0.80[0.71-0.92]$ & $0.85[0.74-0.98]$ & $<.001$ \\
\hline Mean CCA IMT, mm & $0.67[0.59-0.77]$ & $0.71[0.61-0.82]$ & $<.001$ \\
\hline Maximal CCA IMT, mm & $0.79[0.68-0.90]$ & $0.83[0.71-0.96]$ & $<.001$ \\
\hline Mean CB IMT, mm & $0.74[0.62-0.88]$ & $0.80[0.67-0.95]$ & $<.001$ \\
\hline Maximal CB IMT, mm & $0.90[0.75-1.08]$ & $0.96[0.80-1.16]$ & $<.001$ \\
\hline Mean ICA IMT, mm & $0.58[0.50-0.68]$ & $0.62[0.53-0.72]$ & $<.001$ \\
\hline Maximal ICA IMT, mm & $0.70[0.59-0.83]$ & $0.73[0.62-0.87]$ & $<.001$ \\
\hline
\end{tabular}

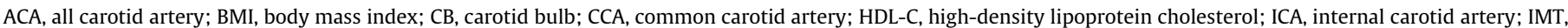
intima-media thickness; REGICOR, Registre Gironi del Cor (Gerona Heart Registry).

Unless otherwise indicated, data are expressed as mean (standard deviation) or median [interquartile range]. 
(ie, CCA, CB, and ICA) and ACA IMT were significantly higher in men. BMI, systolic and diastolic blood pressure, pulse pressure and the prevalence of diabetes, hypertension and smoking were also significantly higher in men, whereas total and HDL-C were significantly higher in women (Table 1 ).
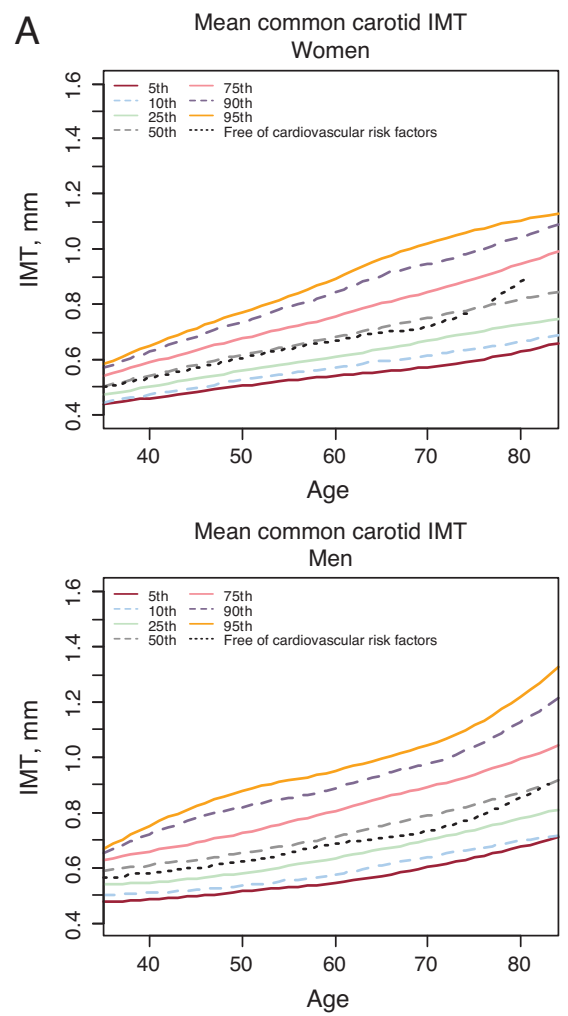

B
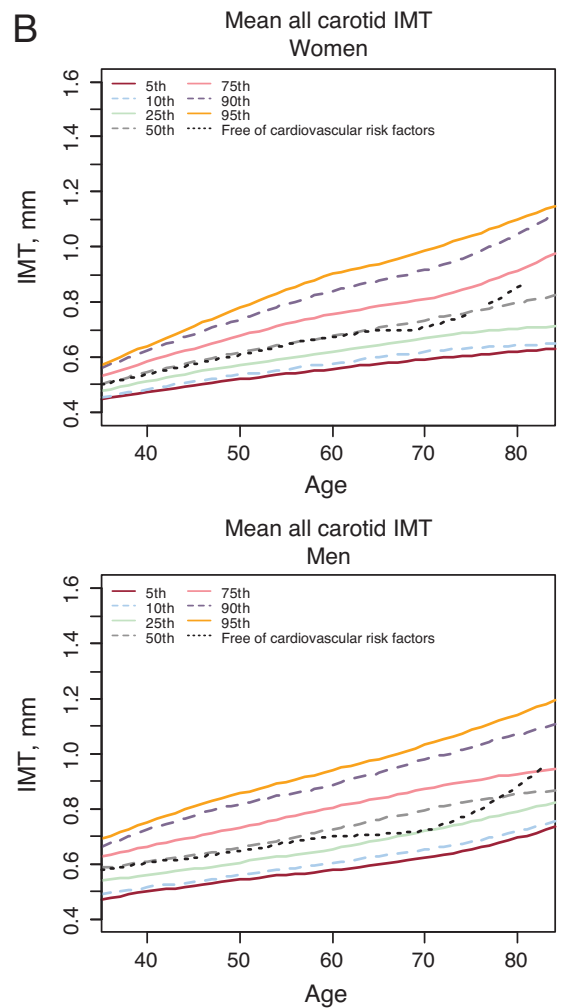

\section{Percentiles of Carotid Intima-media Thickness Measures}

Figure 1 shows the percentiles of mean and maximal CCA and ACA IMT across different ages by sex, respectively. The variability of carotid IMT values (difference between the minimum [5th] and
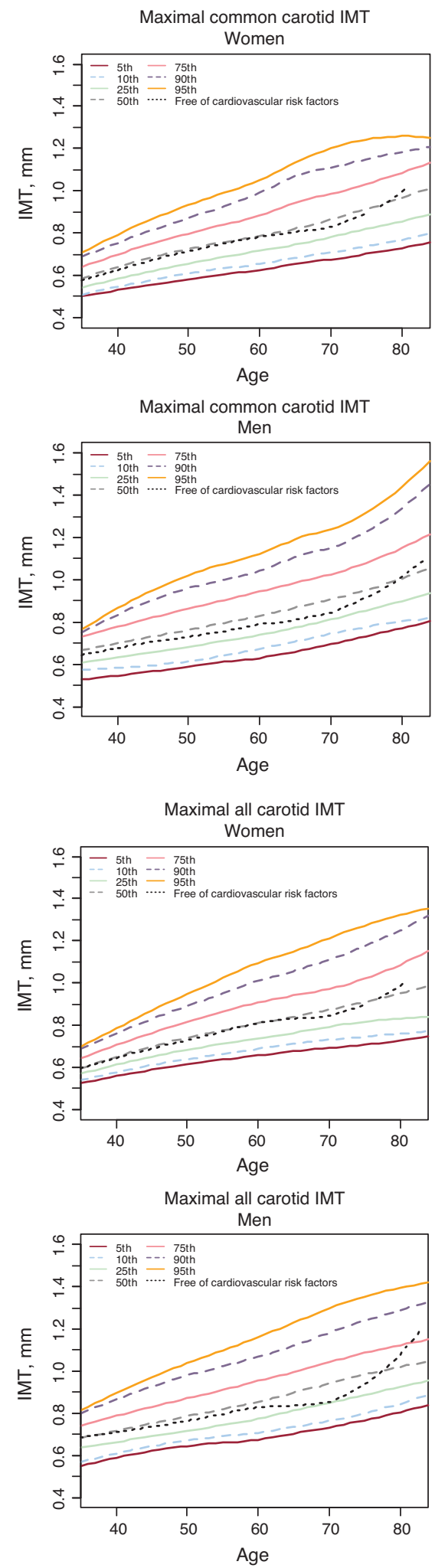

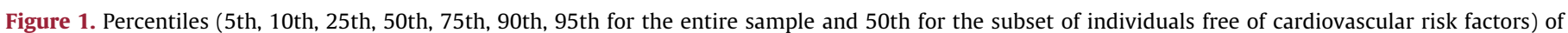

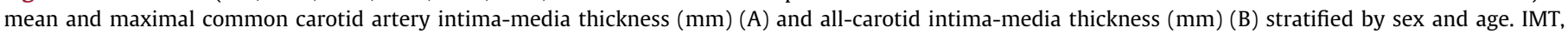
intima-media thickness. 
the maximal [95th] percentiles) tended to increase with age in both sexes. The percentiles of mean and maximal CB and ICA IMT also showed similar trends (Fig. 2 supplementary material). The 50th percentile for the subset of women and men with optimal levels of cardiovascular risk factors ( $n=468$ and $n=306$, respectively) was slightly lower than that observed for all participants. The absolute values defining all percentiles are shown in supplementary material (Tables 1-4).

\section{Association of Carotid Intima-media Thickness With Cardiovascular Risk Factors and 10-Year Coronary Risk}

The estimated coefficients for the crude association of age (10 years) and mean and maximal CCA IMT were $0.73 \mathrm{~mm}(95 \%$ confidence interval [95\%Cl], 0.68-0.78) and $0.81 \mathrm{~mm}(95 \% \mathrm{CI}, 0.75-$ 0.86 ) in women, respectively, and $0.71 \mathrm{~mm}$ (95\%CI, 0.65-0.77) and $0.83 \mathrm{~mm}(95 \% \mathrm{CI}, 0.75-0.91)$ in men. The coefficients for age remained significant when we further adjusted the models for cardiovascular risk factors. We also found significant positive associations of CCA IMT with pulse pressure and BMI in both sexes and with smoking, particularly in men. In contrast, HDL-C showed a significant negative association with CCA IMT only in women (Table 2).

Age (10 years) was also associated with mean and maximal ACA IMT: $0.65 \mathrm{~mm}(95 \% \mathrm{CI}, 0.61-0.70)$ and $0.76 \mathrm{~mm}(95 \% \mathrm{CI}, 0.70-0.82)$ in women, respectively, and $0.67 \mathrm{~mm}(95 \% \mathrm{CI}, 0.62-0.72)$ and $0.81 \mathrm{~mm}$ (95\%CI, 0.74-0.88) in men. Age remained as the main determinant of ACA IMT in the models adjusted for cardiovascular risk factors. Similarly to CCA IMT, ACA IMT showed significant positive associations with pulse pressure in both sexes and with smoking in men, and negative associations with HDL-C in both men and women. In contrast, ACA IMT was also significantly associated with total cholesterol and no association was found with BMI (Table 3). Additional models considering CB IMT and ICA IMT are shown in supplementary material (Tables 5, 6, respectively).

The quartiles of CCA IMT and coronary risk at 10 years showed a consistent correlation across 10-year age groups in individuals aged 35-74 years (Fig. 2). Similarly, significant correlations were found for 10-year coronary risk and the remaining measures of carotid IMT (Figs. 3-5, supplementary material).

\section{DISCUSSION}

In this study we present the reference ranges of mean and maximal carotid IMT in a Spanish population aged 35-84 years free of cardiovascular disease. The availability of reference carotid IMT ranges could be helpful to assess the presence of subclinical disease in clinical practice. In the studied population, carotid IMT measures were systematically higher in men than in women and were associated with age, pulse pressure and HDL-C. In addition, smoking was a significant determinant of carotid IMT only in men. Our results also showed that carotid IMT values consistently correlated with the coronary risk at 10 years estimated by the Framingham-REGICOR risk function. Finally, carotid IMT values in individuals with optimal levels of cardiovascular risk factors may reflect the natural progression of subclinical atherosclerosis.

\section{Comparison With Previous Studies}

A recent European study including 3711 subjects with at least 3 risk factors reported that latitude was an important determinant

Table 2

Association Between Cardiovascular Risk Factors and Average Mean and Maximal Common Carotid Artery Intima-media Thickness (mm) by Sex

\begin{tabular}{|c|c|c|c|c|c|c|c|c|}
\hline & \multicolumn{4}{|c|}{ Women } & \multicolumn{4}{|c|}{ Men } \\
\hline & \multicolumn{2}{|l|}{ Mean CCA IMT } & \multicolumn{2}{|l|}{ Maximal CCA IMT } & \multicolumn{2}{|l|}{ Mean CCA IMT } & \multicolumn{2}{|l|}{ Maximal CCA IMT } \\
\hline & Coefficient (95\%CI) & $P$ & Coefficient $(95 \% \mathrm{CI})$ & $P$ & Coefficient (95\%CI) & $P$ & Coefficient (95\%CI) & $P$ \\
\hline Age & $0.65(0.59-0.71)$ & $<.001$ & $0.71(0.63-0.78)$ & $<.001$ & $0.58(0.51-0.65)$ & $<.001$ & $0.66(0.57-0.75)$ & $<.001$ \\
\hline Smoker & $0.09(-0.09-0.26)$ & .325 & $0.10(-0.11-0.31)$ & .340 & $0.26(0.09-0.43)$ & .003 & $0.26(0.04-0.49)$ & .020 \\
\hline Diabetes & $0.01(-0.22-0.25)$ & .926 & $-0.05(-0.33-0.23)$ & .722 & $0.06(-0.18-0.30)$ & 639 & $0.00(-0.31-0.31)$ & .993 \\
\hline Pulse pressure & $0.08(0.04-0.13)$ & $<.001$ & $0.12(0.06-0.17)$ & $<.001$ & $0.23(0.17-0.29)$ & $<.001$ & $0.31(0.24-0.39)$ & $<.001$ \\
\hline Total cholesterol & $0.00(-0.01-0.02)$ & .708 & $0.01(-0.01-0.03)$ & .457 & $0.00(-0.02-0.03)$ & .656 & $0.01(-0.01-0.04)$ & .372 \\
\hline HDL-C & $-0.08(-0.14$ to -0.03$)$ & .001 & $-0.11(-0.17$ to -0.05$)$ & $<.001$ & $-0.05(-0.14-0.03)$ & .195 & $-0.08(-0.19-0.02)$ & .131 \\
\hline BMI & $0.01(0.00-0.03)$ & .038 & $0.01(0.00-0.03)$ & .150 & $0.03(0.01-0.05)$ & .001 & $0.03(0.00-0.05)$ & .038 \\
\hline
\end{tabular}

BMI, body mass index; CCA, common carotid artery; 95\%CI, 95\% confidence interval; HDL-C, high density lipoprotein cholesterol; IMT, intima-media thickness.

Model adjusted for age (10 years), smoker, diabetes, pulse pressure (10 mmHg), total cholesterol (10 g/dL), HDL-C (10 g/dL) and BMI.

Table 3

Association Between Cardiovascular Risk Factors and Average Mean and Maximal All-carotid Artery Intima-media Thickness (mm) by Sex

\begin{tabular}{|c|c|c|c|c|c|c|c|c|}
\hline & \multicolumn{4}{|c|}{ Women } & \multicolumn{4}{|c|}{ Men } \\
\hline & \multicolumn{2}{|l|}{ Mean ACA IMT } & \multicolumn{2}{|l|}{ Maximal ACA IMT } & \multicolumn{2}{|l|}{ Mean ACA IMT } & \multicolumn{2}{|l|}{ Maximal ACA IMT } \\
\hline & Coefficient (95\%CI) & $P$ & Coefficient (95\%CI) & $P$ & Coefficient (95\%CI) & $P$ & Coefficient (95\%CI) & $P$ \\
\hline Age & $0.57(0.51-0.63)$ & $<.001$ & $0.66(0.58-0.74)$ & $<.001$ & $0.58(0.51-0.64)$ & $<.001$ & $0.69(0.61-0.77)$ & $<.001$ \\
\hline Smoker & $0.10(-0.07-0.26)$ & .269 & $0.20(-0.02-0.42)$ & .071 & $0.22(0.07-0.37)$ & .004 & $0.23(0.03-0.43)$ & .024 \\
\hline Diabetes & $-0.03(-0.26-0.19)$ & .781 & $0.01(-0.27-0.30)$ & .922 & $-0.09(-0.30-0.12)$ & .393 & $-0.14(-0.42-0.14)$ & .326 \\
\hline Pulse pressure & $0.09(0.05-0.14)$ & $<.001$ & $0.12(0.06-0.17)$ & $<.001$ & $0.20(0.15-0.25)$ & $<.001$ & $0.26(0.20-0.33)$ & $<.001$ \\
\hline Total cholesterol & $0.02(0.01-0.04)$ & .008 & $0.03(0.01-0.05)$ & .003 & $0.03(0.01-0.05)$ & .003 & $0.05(0.02-0.07)$ & $<.001$ \\
\hline HDL-C & $-0.06(-0.12$ to -0.01$)$ & .012 & $-0.08(-0.15$ to -0.02$)$ & .011 & $-0.09(-0.16$ to -0.01$)$ & .021 & $-0.10(-0.20$ to -0.01$)$ & .033 \\
\hline BMI & $0.00(-0.01-0.01)$ & .986 & $-0.01(-0.02-0.01)$ & .397 & $0.01(-0.01-0.03)$ & .283 & $0.00(-0.02-0.02)$ & .902 \\
\hline
\end{tabular}

ACA, all carotid artery; BMI, body mass index; 95\%CI, confidence interval; HDL-C, high density lipoprotein cholesterol; IMT, intima-media thickness.

Model adjusted for age (10 years), smoker, diabetes, pulse pressure (10 mmHg), total cholesterol (10 g/dL), HDL-C (10 g/dL) and BMI. 

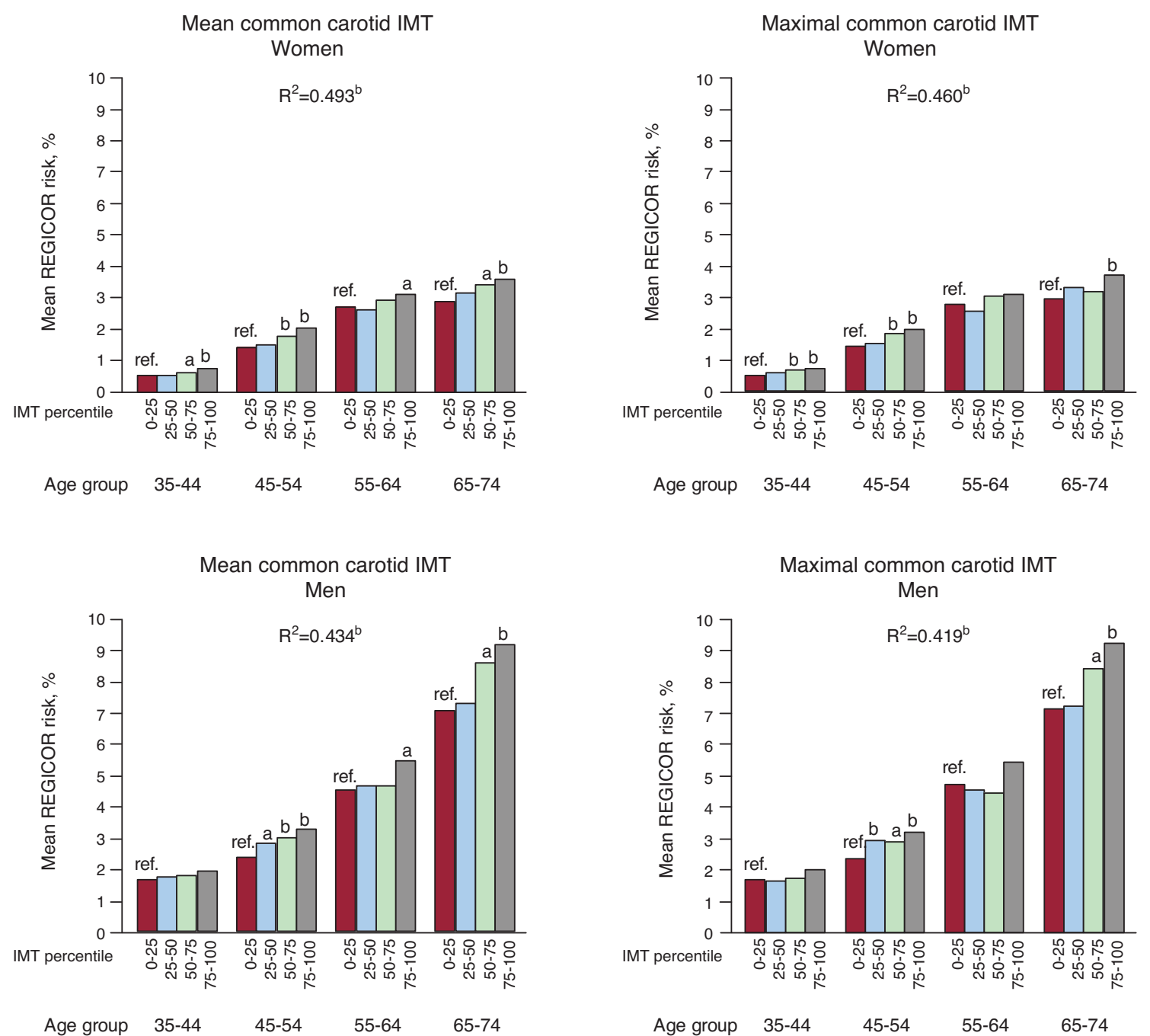

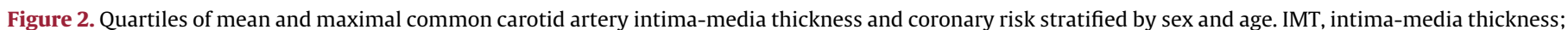
REGICOR, Registre Gironi del Cor (Gerona Heart Registry). ${ }^{\mathrm{a}} \mathrm{P}<.05$; ${ }^{\mathrm{b}} \mathrm{P}<.001$.

of carotid IMT independently of the between-country differences in established cardiovascular risk factors. ${ }^{19}$ Indeed, this association parallels the well-known north-to-south cardiovascular mortality gradient. ${ }^{1}$ Therefore, IMT reference ranges could differ among countries or regions.

Although the proposed reference ranges of carotid IMT are very similar to those described by 2 previous studies also conducted in Spain, those studies presented some important limitations. ${ }^{9,10}$ First, they may have been affected by selection bias because the authors analyzed convenience samples instead of randomly recruited samples. Second, the modest sample size of those studies limited the robustness of estimators, particularly when the analyses were stratified by age group and sex. To guarantee the representativeness of the population, the estimations performed in the present study were based on a much larger sample than in these 2 previous studies, and the participants were randomly selected from the census.

Our results are also similar to those observed in two German studies, Gutenberg Heart ${ }^{16}$ and CAPS (Carotid Atherosclerosis Progression Study), ${ }^{20}$ and in the VITA (Vascular Interventions/ Innovations and Therapeutic Advances) study ${ }^{17}$ from Italy and the ARIC (Atherosclerosis Risk in Communities) study from the United States. ${ }^{5}$ However, the results of the Camp study, also conducted in the Italian population with a maximum of 1 risk factor, were particularly surprising because carotid IMT values were much higher than those we found in the Spanish population. ${ }^{18}$ The Rotterdam Study in the Netherlands also reported higher values than ours; notably, their recruited participants were aged 55 and older. $^{6}$ Therefore, a cautious interpretation of the results found in the most important population-based studies on carotid IMT is required because the age range of participants, the main determinant of carotid IMT, and other inclusion criteria have not been the same in all the studies.

We also provide the reference ranges in a population free of classical cardiovascular risk factors that mainly reflect the natural history of carotid atherosclerosis related to age. These results are also similar to those reported in the Gutenberg-Heart study. ${ }^{16}$

\section{Selection of Cardiovascular Disease Primary Prevention Candidates}

The added value of carotid IMT for cardiovascular risk prediction beyond classical risk factors remains controversial. ${ }^{21,22}$ Several points may suggest the usefulness of carotid IMT for improving cardiovascular risk stratifications. First, this measure is associated with cardiovascular risk factors and coronary risk estimations already observed in previous studies ${ }^{5-7}$ and corroborated in the Spanish population. Second, the correct correlation between carotid IMT and the presence of coronary injuries as 
observed on coronary angiograms could be important. ${ }^{23}$ Finally, carotid IMT has a role as a predictor of cardiovascular disease events observed in several population-based studies ${ }^{5-7}$ and confirmed in a meta-analysis. ${ }^{8}$ However, the performance of carotid IMT for the screening of cardiovascular risk at a population scale is currently under discussion. ${ }^{21}$ Simon et al. ${ }^{22}$ justified this low performance by the modest absolute risk associated with increased carotid IMT (above $1 \mathrm{~mm}$ ), which was $1 \%-2 \%$ per year for coronary heart disease prediction.

To assess the utility of carotid IMT for coronary heart disease risk prediction, several studies have analyzed the discrimination and reclassification capacity beyond classical cardiovascular risk factors with diverse results. For instance, 2 European studies (the CAPS and the Three-City Study) reported no significant improvement in the predictive capacity when including carotid IMT in the models. ${ }^{24,25}$ Conversely, a recent meta-analysis showed that the assessment of carotid plaque resulted in higher diagnostic accuracies for the prediction of future myocardial infarction. ${ }^{26}$ The Three-City Study investigators also pointed out the usefulness of ultrasound assessment of carotid plaques for coronary heart disease risk prediction. ${ }^{25}$ However, the results of the ARIC Study suggest that not only the inclusion of the carotid IMT values improves the predictive properties of the models over considering classical cardiovascular risk factors only, ${ }^{27}$ but also the presence of atherosclerotic plaque. ${ }^{28}$

\section{Association With Classical Risk Factors}

In this study, age was the strongest determinant of carotid IMT. This association was very clear in the subgroup of participants without risk factors. Similar to other studies, ${ }^{16}$ sex was also associated with IMT, with men showing higher values than women across all ages. Classical risk factors were consistently associated with carotid IMT in both men and women. Our results concur with those recently reported in the IMPROVE study, in which sex, age, smoking, and pulse pressure were the strongest determinants of carotid IMT. ${ }^{19}$ The authors of the EVA (The Vascular Aging) study pointed out that pulse pressure may reflect an increase in arterial stiffness and could be a better predictor than systolic blood pressure, particularly in elderly subjects. ${ }^{29}$

The lack of association between smoking and IMT in women in our study could be related to the inverse association between smoking prevalence and age in women.

\section{Limitations}

This study has several potential limitations. First, we described the reference ranges of carotid IMT in Spain using a single-center cohort from an area in north-eastern Spain. However, previous studies have shown that the variability in the prevalence of cardiovascular risk was relatively low across Spain's autonomous communities. ${ }^{30}$ Therefore, similarly minor differences should be expected in carotid IMT values in the same context. In addition, a similar single-area design has been used to provide reference values for carotid IMT in Italy and Germany. ${ }^{16,17}$ Second, selection bias may affect any cross-sectional study, but is likely to be modest in magnitude in this case since the study was population-based and the participants were not selected on the basis of the presence or absence of altered carotid IMT. Third, the cross-sectional design does not allow estimation of causal association. Further population-based cohort studies are needed in southern Europe to ascertain the causal association between carotid IMT progression and the incidence of cardiovascular events and to possibly define the cut-off point to start an aggressive intervention. All the carotid IMT measures in this study were done according to a standard protocol validated in previous studies ${ }^{13}$ and were interpreted by the same senior reader to avoid measurement errors. However, differences in the ultrasound technology, image capture, carotid artery segmentation and method of measuring IMT could introduce variability affecting the results.

\section{CONCLUSIONS}

The results of this population-based study show the reference ranges of carotid IMT in the Spanish population. The main determinants of carotid IMT were age and pulse pressure. In addition, coronary risk increased with the quartiles of carotid IMT independently of age.

\section{ACKNOWLEDGMENTS}

The authors are grateful to Susanna Tello, Marta Cabañero and Leny Franco, for project and data management. We also appreciate the revision of the English text by Elaine Lilly, Phd of Writer's First Aid.

\section{FUNDING}

This research was supported by funding from the Government of Spain through the Ministerio de Ciencia e Innovación, Instituto de Salud Carlos III,, European Regional Development Fund (Red HERACLES RD06/0009); Fondo de Investigación Sanitaria (FIS PI081327, FIS PI060258); CIBERESP, and Rio-Hortega (CM0800141); Fundació La Marató de TV3 (081632); Agència de Gestió Ajuts Universitaris de Recerca (2009 SGR 1195) and Beca de la Fundación Española del Corazón, Fuente Liviana and Sociedad Española de Cardiología 2011.

\section{CONFLICTS OF INTEREST}

None declared.

\section{SUPPLEMENTARY MATERIAL}

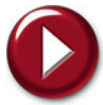

Supplementary material associated with this article can be found in the online version available at: http:// dx.doi.org/10.1016/j.rec.2012.04.019.

\section{REFERENCES}

1. World Health Statistics. Monograph on the Internet. Geneva: World Health Organization; 2011 [cited 2011 Oct 13]. Available at: https://apps.who.int infobase/

2. Hansson GK. Inflammation, atherosclerosis, and coronary artery disease. N Engl J Med. 2005;352:1685-95.

3. Touboul PJ, Hennerici MG, Meairs S, Adams H, Amarenco P, Bornstein N, et al. Mannheim carotid intima-media thickness consensus (2004-2006). An update on behalf of the Advisory Board of the 3rd and 4th Watching the Risk Symposium, 13th and 15th European Stroke Conferences, Mannheim, Germany, 2004 and Brussels, Belgium, 2006. Cerebrovasc Dis. 2007;23:75-80.

4. Stein JH, Korcarz CE, Hurst RT, Lonn E, Kendall CB, Mohler ER, et al. Use of carotid ultrasound to identify subclinical vascular disease and evaluate cardiovascular disease risk: a consensus statement from the American Society of Echocardiography Carotid Intima-Media Thickness Task Force. Endorsed by the Society for Vascular Medicine. J Am Soc Echocardiogr. 2008;21:93-111.

5. Chambless LE, Heiss G, Folsom AR, Rosamond W, Szklo M, Sharrett AR, et al Association of coronary heart disease incidence with carotid arterial wall thickness and major risk factors: the Atherosclerosis Risk in Communities (ARIC) Study, 1987-1993. Am J Epidemiol. 1997;146:483-94.

6. Bots ML, Hoes AW, Koudstaal PJ, Hofman A, Grobbee DE. Common carotid intima-media thickness and risk of stroke and myocardial infarction: the Rotterdam Study. Circulation. 1997;96:1432-7. 
7. O’Leary DH, Polak JF, Kronmal RA, Manolio TA, Burke GL, Wolfson Jr SK. Carotidartery intima and media thickness as a risk factor for myocardial infarction and stroke in older adults. Cardiovascular Health Study Collaborative Research Group. N Engl J Med. 1999;340:14-22.

8. Lorenz MW, Markus HS, Bots ML, Rosvall M, Sitzer M. Prediction of clinical cardiovascular events with carotid intima-media thickness: a systematic review and meta-analysis. Circulation. 2007;115:459-67.

9. Junyent M, Gilabert R, Núñez I, Corbella E, Vela M, Zambón D, et al. Ecografía carotídea en la evaluación de aterosclerosis preclínica. Distribución de valores del grosor íntima-media y frecuencia de placas de ateroma en una cohorte comunitaria española.. Med Clin (Barc). 2005;125:770-4.

10. Jarauta E, Mateo-Gallego R, Bea A, Burillo E, Calmarza P, Civeira F. Grosor íntima-media carotídeo en sujetos sin factores de riesgo cardiovascular. Rev Esp Cardiol. 2010;63:97-102.

11. Gómez-Marcos MA, Recio-Rodríguez JI, Rodríguez-Sánchez E, Patino-Alonso MC, Magallón-Botaya R, Martínez-Vizcaino V, et al. Grosor íntima-media carotídeo en diabéticos e hipertensos. Rev Esp Cardiol. 2011;64:622-5.

12. Grau M, Subirana I, Elosua R, Solanas P, Ramos R, Masiá R, et al. Trends in cardiovascular risk factor prevalence (1995-2000-2005) in northeastern Spain. Eur J Cardiovasc Prev Rehabil. 2007;14:653-9.

13. De Groot E, Van Leuven SI, Duivenvoorden R, Meuwese MC, Akdim F, Bots ML, et al. Measurement of carotid intima-media thickness to assess progression and regression of atherosclerosis. Nat Clin Pract Cardiovasc Med. 2008;5 280-8.

14. Su YS, Gelman A, Hill J, Yajima M. Multiple imputation with diagnostics (mi) in R: Opening windows into the black box. J Stat Softw. 2011;45. pii: v45/i02.

15. Marrugat J, Subirana I, Comín E, Cabezas C, Vila J, Elosua R, et al. Validity of an adaptation of the Framingham cardiovascular risk function: the VERIFICA Study. J Epidemiol Community Health. 2007;61:40-7.

16. Sinning C, Wild PS, Echevarria FM, Wilde S, Schnabel R, Lubos E, et al. Sex differences in early carotid atherosclerosis (from the community-based Gutenberg-Heart Study). Am J Cardiol. 2011;107:1841-7.

17. Tosetto A, Prati P, Baracchini C, Manara R, Rodeghiero F. Age-adjusted reference limits for carotid intima-media thickness as better indicator of vascular risk: population-based estimates from the VITA project. J Thromb Haemost. 2005;3:1224-30.

18. Ciccone MM, Balbarini A, Teresa Porcelli M, Santoro D, Cortese F, Scicchitano P et al. Carotid artery intima-media thickness: normal and percentile values in the Italian population (camp study). Eur J Cardiovasc Prev Rehabil. 2011;18:650-5.

19. Baldassarre D, Nyyssönen K, Rauramaa R, De Faire U, Hamsten A, Smit AJ, et al.; IMPROVE study group. Cross-sectional analysis of baseline data to identify the major determinants of carotid intima-media thickness in a European population: the IMPROVE study. Eur Heart J. 2010;31:614-22.

20. Lorenz MW, Von Kegler S, Steinmetz H, Markus HS, Sitzer M. Carotid intimamedia thickening indicates a higher vascular risk across a wide age range: prospective data from the Carotid Atherosclerosis Progression Study (CAPS). Stroke. 2006;37:87-92.

21. Plantinga Y, Dogan S, Grobbee DE, Bots ML. Carotid intima-media thickness measurement in cardiovascular screening programmes. Eur J Cardiovasc Prev Rehabil. 2009;16:639-44.

22. Simon A, Megnien JL, Chironi G. The value of carotid intima-media thickness for predicting cardiovascular risk. Arterioscler Thromb Vasc Biol. 2010;30:182-5.

23. Granér M, Varpula M, Kahri J, Salonen RM, Nyyssönen K, Nieminen MS, et al Association of carotid intima-media thickness with angiographic severity and extent of coronary artery disease. Am J Cardiol. 2006;97:624-9.

24. Lorenz MW, Schaefer C, Steinmetz H, Sitzer M. Is carotid intima media thickness useful for individual prediction of cardiovascular risk? Ten-year results from the Carotid Atherosclerosis Progression Study (CAPS) Eur Heart J. 2010;31:2041-8.

25. Plichart M, Celermajer DS, Zureik M, Helmer C, Jouven X, Ritchie K, et al. Carotid intima-media thickness in plaque-free site, carotid plaques and coronary heart disease risk prediction in older adults. The Three-City Study. Atherosclerosis. 2011;219:917-24.

26. Inaba Y, Chen JA, Bergmann SR. Carotid plaque, compared with carotid intimamedia thickness, more accurately predicts coronary artery disease events: a meta-analysis. Atherosclerosis. 2012;220:128-33.

27. Nambi V, Chambless L, He M, Folsom AR, Mosley T, Boerwinkle E, et al. Common carotid artery intima-media thickness is as good as carotid intima-media thickness of all carotid artery segments in improving prediction of coronary heart disease risk in the Atherosclerosis Risk in Communities (ARIC) study. Eur Heart J. 2012;33:183-90.

28. Nambi V, Chambless L, Folsom AR, He M, Hu Y, Mosley T, et al. Carotid intimamedia thickness and presence or absence of plaque improves prediction of coronary heart disease risk: the ARIC (Atherosclerosis Risk In Communities) study. J Am Coll Cardiol. 2010;55:1600-7.

29. Zureik M, Touboul PJ, Bonithon-Kopp C, Courbon D, Berr C, Leroux C, et al. Crosssectional and 4-year longitudinal associations between brachial pulse pressure and common carotid intima-media thickness in a general population. The EVA study. Stroke. 1999;30:550-5.

30. Grau M, Elosua R, Cabrera de León A, Guembe MJ, Baena-Díez JM, Vega Alonso T, et al. Factores de riesgo cardiovascular en España en la primera década del siglo xxI: análisis agrupado con datos individuales de 11 estudios de base poblacional, estudio DARIOS. Rev Esp Cardiol. 2011;64:295-304. 